\title{
MEMÓRIA E ESQUECIMENTO NO PÓS-GUERRA
}

Roberta Saçço ${ }^{1}$

RESUMO: O presente artigo pretende discutir a relação entre memória e esquecimento no pós-guerra. Nossa proposta é entender como o aumento explosivo de memória que marcou o final do século XX não conseguiu romper com o esquecimento, ao contrário, fomos acometidos por uma onda de amnésia, apatia e perda da consciência histórica. Nossas hipóteses se baseiam nos estudos de ADORNO (1969), FREUD (1911-1913), HUYSSEN (2010) e SELIGMANN-SILVA (2005).

Palavras-chave: Holocausto; ditadura militar; memória; esquecimento.

ABSTRACT: El presente artículo pretende discutir la relación entre memoria y olvido en la posguerra. Nuestra propuesta es entender cómo el aumento explosivo de memoria que marcó el final del siglo XX no logró romper con el olvido, al contrario, fuimos acometidos por una ola de amnesia, apatía y pérdida de la conciencia histórica. Nuestras hipótesis se basan en los estudios de ADORNO (1969), FREUD (1911-1913), HUYSSEN (2010) y SELIGMANN-SILVA (2005).

Palabras clave: Holocausto; dictadura militar; memoria; olvido.

\section{Introdução}

Buscamos neste artigo discutir a relação das sociedades pós-guerra com a memória. Nosso objetivo é fazer uma reflexão teórica sobre os processos de memorialização do Holocausto e das ditaduras latino-americanas, de modo especial o Brasil, sob a ótica do testemunho. Entender como o aumento explosivo de memória que marcou o final do século XX não conseguiu romper com o esquecimento. Embora nossos objetos tenham influências de fatores externos, específicos da história de cada região, tomaremos o Holocausto como lugar-comum da memória traumática que marcou o final do século XX. O referencial teórico que norteará nossa investigação considera os estudos de HUYSSEN (2010) e sua associação com ADORNO (1969) para que possamos entender a emergência da memória do Holocausto e sua relação com a indústria cultural. No caso latino-americano, fundamentaremos nossas análises em SELIGMANN-SILVA (2005). O autor propõe reflexões sobre o testemunho,

\footnotetext{
${ }^{1}$ Mestra e Doutoranda em Estudos Literários pelo Programa de Pós-Graduação em Letras da Universidade Federal de Juiz de Fora, UFJF
} 
tanto na Europa e nos Estados Unidos quanto na América Latina e correlata seus estudos com a perspectiva freudiana do trauma.

Nossa proposta é reunir e confrontar as leituras dos dois teóricos que possuem um trabalho já amadurecido sobre o tema fazendo um encontro entre o passado ditatorial da América Latina e o Holocausto, destacando a relação entre esses dois eventos históricos e priorizando o caso brasileiro.

\section{O Holocausto como lugar comum}

De acordo com o crítico alemão Andreas Huyssen o Holocausto, enquanto evento histórico, foi banalizado pela especularização e pela mercadorização em torno de sua memória. A partir desses conceitos, nortearemos nossa discussão tendo como base teórica a obra Seduzidos pela memória, HUYSSEN (2000), na qual o autor desenvolve sua argumentação em torno da noção de musealização da memória. Segundo ele, a memória está sujeita a abusos políticos e também econômicos.

$\mathrm{O}$ enfoque sobre o passado no final do século XX é marcado pelos discursos de memória de nações que lutam para criar políticas democráticas sob os destroços dos regimes de exceção. De acordo com HUYSSEN (2000), o movimento testemunhal na Europa se inicia com o discurso do presidente da Alemanha, Richard von Weizsäcker, que inaugura um amplo debate sobre o Holocausto. Em 1985, no $40^{\circ}$ aniversário da derrota alemã, Weizsäcker afirmou que o 8 de maio de 1945 marcou "a libertação do sistema que menospreza a dignidade humana". Mais tarde, uma série de eventos internacionais na Europa e no Japão, entre eles a queda do muro de Berlim (1989), a unificação nacional da Alemanha (1990), trouxeram novamente a cena da Segunda Guerra para o centro das discussões mundiais ao receber intensa cobertura da mídia internacional. Acontece, nesse momento, o que o autor chama de globalização do discurso do Holocausto. Para HUYSSEN (2000), o Holocausto se transformou numa metáfora do século XX, a qual atesta a incapacidade humana de conviver em paz com as diferenças. Para o autor é a representação da falência do projeto iluminista, com seus ideais de liberdade individual, tolerância religiosa e fraternidade. 


\begin{abstract}
Por um lado, o Holocausto se transformou numa cifra para o século XX como um todo e para falência do projeto iluminista. Ele serve como uma prova da incapacidade da civilização ocidental de praticar a anamnese, de refletir sobre sua inabilidade constitutiva para viver em paz com as diferenças e alteridades e de tirar as consequências das relações insidiosas entre a modernidade iluminista, a opressão racial e a violência organizada (HUYSSEN, 2000, p. 12-13).
\end{abstract}

Ao mesmo tempo, a emergência do Holocausto como lugar comum universal permite que comecemos a entender situações locais específicas, historicamente e politicamente distintas do evento original. "É o pré-requisito para o seu descentramento e seu uso como um poderoso prisma através do qual podemos olhar outros exemplos de genocídios" (HUYSSEN, 2000, p. 13).

A ideia de Huyssen é que a partir do Holocausto possamos entender outras tramas secundárias, no nosso caso as ditaduras nos países latinoamericanos. A Segunda Guerra Mundial marcou uma época de grandes catástrofes históricas: as guerras de independência na África, as ditaduras na América Latina, o apartheid na África do Sul, as guerras do Golfo, do Kosovo, da Bósnia, entre outros conflitos armados. Nesse contexto, a memória passa a ser uma preocupação cultural e política. E a partir da década de 1980 novos movimentos sociais surgem em busca de revisionismo histórico.

Embora a cena fosse propícia para o revisionismo, ele não aconteceu. Ao contrário, fomos acometidos por uma amnésia e uma apatia que acabaram por banalizar o evento histórico. Huyssen destaca a comercialização da memória pela indústria cultural do ocidente como responsável por esse processo. Segundo ele, desde a década de 1970 podemos observar na Europa e nos Estados Unidos uma obsessiva musealização do mundo. "Não há dúvidas de que o mundo está sendo musealizado e que todos nós representamos os nossos papeis nesse processo" (HUYSSEN, 2000, p.15).

O debate em torno dessa questão apoia-se em Theodor Adorno que em sua obra Dialética do Esclarecimento analisa a mercantilização da cultura, ou seja, a transformação da cultura em mercadoria. Nesse caso, Adorno tem como foco a música, no entanto, qualquer produto cultural está passivo de ser transformado em mercadoria e não há como fugirmos disso, "o mundo inteiro é forçado a passar pelo filtro da indústria cultural” (ADORNO, 1969, p.59), e completa "A violência da sociedade industrial instalou-se nos homens de uma vez por todas. Os produtos da indústria cultural podem ter a certeza de que até mesmo os distraídos 
vão consumi-los abertamente" (HUYSSEN, 2000, p.60). O que Huyssen completa: "não há espaço puro fora da cultura da mercadoria, por mais que possamos desejar tal espaço" (HUYSSEN, 2000, p. 21).

No entanto, para Huyssen, a crítica de Adorno é correta no que se refere à comercialização em massa dos produtos culturais, mas não explica o crescimento da síndrome da memória dentro da indústria cultural. Segundo ele, ao se debruçar sobre as categorias marxistas de valor de troca e reificação, Adorno acaba por não dar a devida atenção às especificidades da mídia e sua relação com as sociedades de consumo.

Dentre os principais sintomas dessa nova relação entre memória e esquecimento estão o capital e a mídia, o que faz com que Huyssen questione o por que o aumento explosivo de memória no pós-guerra está associado ao aumento proporcional de esquecimento. De acordo com autor o excesso de memória nessa cultura saturada de mídia pode causar a sobrecarga do sistema de memórias e produzir o esquecimento. Quanto mais somos levados a lembrar, mais sentimos a necessidade de esquecer e, tentamos combater esse medo com estratégias de rememoração públicas e privadas. O fato é que nossa cultura está obcecada com a memória por medo do esquecimento (HUYSSEN, 2000, p. 20).

O autor nos leva a pensar a mídia como produtora de memória em escala industrial, assim, questões importantes da cultura contemporânea passam a fazer parte de um repertório midiático que emociona e vende. Há um público que consome memória. Segundo o autor, o trauma é comercializado tanto quanto divertimento e para o mesmo público. Em suma, a síndrome da memória pode ser explicada a partir dos interesses de lucro dos comerciantes da memória. Para o passado há mercado consumidor, “...o passado está vendendo mais que o futuro" (HUYSSEN, 2000, p. 24).

Mas, o fato do passado atrair os olhares da mídia e da indústria cultural por seu alto poder mercadológico não é, em si, um argumento convincente para justificar a onda de amnésia e esquecimento que assombra a modernidade. Huyssen acredita que nessa relação entre mídia e memória exista algo que deva ser pensado, algo que nos faz privilegiar o passado e atender tão prontamente aos mercados da memória, mas ao mesmo tempo, há algo que nos permite fazer uma reflexão sobre os processos históricos. Segundo o autor, é possível que o excesso de memória em nossa cultura, saturada de mídia, crie uma sobrecarga que 
coloque o próprio sistema de memórias em perigo constante de implosão, disparando o medo do esquecimento (HUYSSEN, 2000, p. 19).

Contudo, o debate em torno do esquecimento ganha novos contornos na América Latina uma vez que o debate não foi instaurado como no caso Europeu. Como descrito anteriormente, o testemunho na Europa tem início com a declaração de um presidente alemão condenando o Holocausto. Neste caso, há uma responsabilização do governo pelos crimes cometidos e o país instaura um período de revisionismo histórico. De acordo com SELIGMANN (2005), o testemunho acerca do Holocausto na Europa tem desempenhado alguns papéis, tais como: fazer justiça, documentar a história, reelaborar um passado traumático, cooperar para a reconstrução da identidade de um grupo de pessoas (judeus) que reencontram sua identidade na memória coletiva da catástrofe. "O testemunho funciona como guardião da memória” (SELIGMANN, 2005, p.88). Neste caso, já não há uma disputa de memória entre a vítima e o algoz, como ainda acontece no Brasil, por exemplo.

Ainda segundo o autor, o conceito de testemunho ganhou diferentes contornos de acordo com cada região. Nas pesquisas realizadas nos Estados Unidos e na Europa, a psicanálise e a teoria e história da memória têm desempenhado o papel principal; já na América Latina, o testemunho é pensado a partir de tradições religiosas. Ainda estamos atestando se o que aconteceu foi verídico, estamos colhendo depoimentos, atestando a validade legal dos fatos. Estamos instaurando um debate tardio.

Na Europa a noção de testemunho foi desenvolvida a partir da perspectiva teórica de Theodor Adorno que coloca em questão a impossibilidade de se escrever poesia após Auschwitz paralela à necessidade de se narrar a barbárie. Neste contexto, o foco recai sobre a linguagem, mais especificamente, sobre sua insuficiência diante do horror. Focalizando essa discussão em torno da Shoah: o assassinato de milhões de Judeus em campos de concentração na Alemanha, pelos nazistas o testemunho se articula em torno da reconstrução de uma memória fragmentada.

O discurso testemunhal europeu e norteamericano tem sido pensado a partir de leituras que envolvem a teoria da literatura, história, teoria psicanalítica e os estudos da memória, os quais têm ganhado mais espaço nas últimas décadas. Neste caso, o testemunho é uma tentativa de reunir os fragmentos do passado. Talvez esse excesso de estímulo, sob os poderes 
do capital e sua especulação, tenham levado a banalização, como defende Andreas Huyssen. O boom da memória acabou chamando a atenção da indústria cultural que viu nela uma oportunidade de comercialização crescente e bem-sucedida, o que acabou por manipular o discurso político. Uma obsessiva musealização tomou conta da Europa e dos Estados Unidos trazendo o que HUYSSEN (2000) chama de entretenimento memorialístico do trauma.

A diferença do papel da mídia no Brasil é que ela não viu na memória uma oportunidade comercial, no sentido de comercialização do produto cultural. A mídia brasileira sempre esteve a serviço do capital, mas de outra forma. Nossa mídia é manipuladora, ela se associa ao poder e a ele presta serviços de desinformação, tanto o fez no período 1964-1985 quanto continuou a fazer após o final do regime de exceção. Ela manipula a população e vende o discurso oficial, reprimindo toda e qualquer iniciativa de debate público que contrarie seus interesses. No processo de redemocratização foi peça fundamental e continua agindo como agia a mais de 50 anos atrás, apoiando golpes e servindo à elite dominante. E que fique claro que não estamos desconsiderando a censura imposta aos meios de comunicação durante o regime militar. Eles dispunham de outra função, seu foco era voltado a coibir a produção cultural e artística que afrontava o sistema. A mídia, na verdade, se aproveitava da censura para justificar seu silêncio com relação às graves violações dos direitos humanos cometidas pelo Estado naquela época.

Como podemos verificar tanto HUYSSEN (2000), quanto SELLIGMANN (2005), atribuem a mídia um papel manipulador. A mídia sempre se associa ao capital e provoca nas sociedades danos irreparáveis. No caso do Holocausto, os estudos de Andreas Huyssen nos mostram que a comercialização da memória pela indústria cultural banalizou o evento histórico. Já Márcio Seligmann-Silva desenvolve suas pesquisas em torno do testemunho, que não caso brasileiro não aconteceu em virtude da associação dos donos do poder em torno de um silêncio imposto à redemocratização. Mais uma vez a mídia se associa ao capital, mas, dessa vez, ao se aliar aos donos do poder para manipular as informações e ajudar a construir o discurso oficial contra as vítimas, calando-as, a favor dos algozes.

Voltando a SELIGMANN (2005), há na teoria literária dois grandes campos de discurso sobre o testemunho, que têm se aproximado nos últimos anos. Por um lado, como vimos anteriormente, a questão é pensada sob o prisma europeu e norteamericano, 
considerando-se a memória em torno da Segunda Guerra Mundial e da Shoah. E por outro lado, considera-se as experiências históricas e literárias da América Latina, representadas pelas ditaduras e a repressão às minorias (mulheres, negros e homossexuais). Paralelamente à expansão dos Estudos Culturais, o conceito de testemunho se ampliou: passou a tratar não apenas dos sobreviventes da Shoah, mas também dos sobreviventes de outras guerras e genocídios.

Assim, de acordo com SELLIGMANN (2005), na América Latina o conceito de testemunho insere-se no contexto da contra-história, ou seja, centra-se na denúncia, e, nesse contexto, a ênfase recai sobre a testemunha capaz de provar e certificar a verdade dos fatos. Pode-se também falar na América Latina da necessidade de testemunhar, pois o testemunho cumpre a necessidade de se fazer justiça, de nomear como heroi aquele ou aquela que foi considerado (a) como subversivo (a) pela ditadura militar, e assim dar voz ao oprimido.

\section{As políticas do esquecimento no Brasil}

A partir desse conceito de testemunho, nossa análise parte do pressuposto que no Brasil não temos uma cultura da memória. A ausência do testemunho no Brasil se deu pelo fato das vítimas terem sido tiradas da cena política e colocadas à margem do processo. Ainda hoje, mais de três décadas pós-ditadura a sociedade brasileira não conseguiu instituir o debate, "não há processo aqui; apenas estancamento" (SELIGMANN, 2010, p. 13). De acordo com Márcio Seligmann-Silva a passagem pelo testemunho é fundamental tanto para o indivíduo quanto para as sociedades que viveram experiências-limites, "O testemunho pode, justamente, servir de caminho para a construção de uma identidade pós-catástrofe" (SELIGMANN, 2010, p.12).

O que podemos ver hoje no Brasil com a criação da Comissão Nacional da Verdade e de outras comissões locais é uma tentativa de fazer emergir o debate sobre o que representou a ditadura civil-militar que se instaurou no Brasil por 21 anos. O relatório final da Comissão Nacional da Verdade ${ }^{2}$, publicado em 10 de dezembro de 2014 revela o processo de

2 Comissão Nacional da Verdade (CNV) é o nome da comissão que investigou as graves violações de direitos humanos cometidas entre 18 de setembro de 1946 e 05 de outubro de 1988 , por "agentes públicos, pessoas a seu serviço, com apoio ou no interesse do Estado". 
desumanização à que eram submetidos os opositores ao regime: torturas físicas e psicológicas, desaparecimentos forçados e mortes. Através de relatos de vítimas ou parentes de desaparecidos políticos o Brasil começou a construir o discurso sob a ótica do oprimido, o qual através da narração dos momentos de dor buscou contribuir para o processo de reescrita da história no Brasil.

Países como Argentina, Chile e Uruguai conseguiram levar aos tribunais os casos de violação dos direitos humanos oriundos das ditaduras militares. Enquanto nesses países há uma vasta produção de cunho testemunhal, no Brasil há apenas obras isoladas que não conseguem sequer espaço de destaque nas livrarias. O fato é que no Brasil não houve um reconhecimento público nos erros do passado. Ainda há uma disputa de memória entre torturador e torturado que perdura desde a redemocratização, de acordo com SELIGMANN (2005), na América Latina tivemos e, no Brasil, ainda temos, a necessidade de nomear como heroi aquele que foi considerado subversivo. As forças armadas ainda insistem na teoria de revolução democrática, impedindo a instauração do debate. Assim, o silêncio da testemunha produziu o esquecimento e a apatia. O esquecimento por aqui foi imposto. Isso porque ao monopolizar a transição, as elites também monopolizaram os discursos. Desde então o que se verifica é uma ausência do testemunho.

De acordo com SELIGMANN (2010), no Brasil as vítimas foram silenciadas e retiradas da cena política, aqueles que lutaram pela redemocratização foram colocados à margem do discurso e entregues a políticas do esquecimento. Por fim, os criminosos conseguiram, com a ajuda da mídia, convencer a sociedade de que dar lugar ao testemunho das vítimas da ditadura alimentaria o desejo de vingança por parte dos militantes e seus familiares, "as elites simplesmente decidiram que a página da história deve ser virada. Elas estigmatizam as tentativas de se estabelecer a verdade e a justiça como meros atos de revanchismo" (SELLIGMANN, 2010, p. 13).

O Brasil acreditou que conseguiria reestabelecer a democracia passando por cima da sua história traumática, considerou que o esquecimento fosse uma saída. No entanto, o que observamos é a repetição dos mesmos erros do passado, eles se atualizam e sempre voltam em forma de golpes e supressão do processo democrático. A falta de consciência histórica no Brasil não começou com o golpe de 64, ela intrínseca na sociedade brasileira, desde a 
colonização com a exploração dos recursos naturais, com massacre indígena e com a instauração da pior de todas as nossas barbáries: a escravidão.

Golpes fazem parte da tradição política brasileira. Um infográfico publicado na revista Fórum aponta que a tradição no Brasil é o golpe. Desde o golpe militar de Deodoro da Fonseca, que deu origem à República, até o governo de Dilma Rousseff, nossa república viveu 76 anos não-exatamente-democráticos, contra 50 anos de "democracia". Se considerarmos os 19 anos entre 1945 e 1964, período anterior ao golpe militar, conhecido como república liberal, foram 12 presidentes, sendo 6 deles interinos, e apenas dois dos que foram eleitos terminaram o mandato: o general Enrico Gaspar Dutra (1946-1951) e Juscelino Kubitschek (1956-1961). A seguir foram 21 anos da ditadura (1964-1985), seguidos de um novo período "democrático", instaurado por uma eleição indireta, que elegeu Tancredo Neves, falecido antes de tomar posse. Após a sua morte, em 21 de abril de 1985, os mesmos atores da ditadura se mantiveram no poder. José Sarney assumiu a presidência da República do Brasil. Considera-se sobre a presidência de Sarney (1985-1990) que se reinstalou um período democrático no Brasil, mas lembremos de que ele era ministro dos militares. A primeira eleição direta após o fim do regime militar foi em 1989, quando Collor foi eleito. Depois disso, mesmo com o impeachment de Collor, o Brasil viveu uma brisa democrática fortemente abalada agora por um novo processo de impedimento, dessa vez um novo golpe travestido de impeachment.

Mas o que não esperávamos é o que Freud sempre nos alertou em relação à compulsão à repetição. Se aplicarmos a teoria freudiana à história do Brasil, se pensarmos o Brasil como um coletivo e o colocarmos num Divã, chegaremos a conclusões óbvias. Nosso passado se repete por falta de elaboração.

FREUD (1911-1913), em Recordar, repetir elaborar, nos explica que a repetição é uma transferência do passado esquecido, e substitui a recordação, "logo notamos que a transferência mesma é somente uma parcela de repetição, e que a repetição é transferência do passado esquecido" (FREUD, 1911-1913, p. 150). Recordamos aquilo que pode ser lembrado enquanto repetimos o recalcado. Ou seja, o paciente traumatizado, repete ao invés de recordar, para ele a compulsão a repetição é uma maneira de recordação. Quanto mais o paciente resiste, menos ele recorda e mais ele repete, pois o recordar ideal do que foi esquecido 
corresponde a um estado em que a resistência foi totalmente afastada. A superação das resistências tem início quando o paciente é comunicado sobre ela, depois ele precisa de tempo para superar, "nomear a resistência não pode conduzir à sua imediata cessação. É preciso dar tempo ao paciente para que ele se enfronhe na resistência agora conhecida, para que a elabore" (FREUD, 1911-1913, p. 154).

Nesse momento da análise, quando o paciente vence a resistência, Freud lança mão de outro conceito, tão importante quanto a repetição e a recordação: o de elaboração. A elaboração é uma forma de vencer a resistência. O paciente ao rememorar eventos traumáticos se torna consciente, racionaliza seu comportamento. Assim, ele acessa o recalcado e transforma, de forma simbólica e consciente, a lembrança em recordação, e não mais repete o recalque. Essa elaboração se dá via linguagem.

Concluímos, a partir da teoria freudiana, que o Brasil é um país recalcado. Por não elaborar seus traumas, estamos sempre a repeti-los. É preciso colocar o Brasil no divã, é preciso olhar para nosso passado com olhar atento e crítico. Reconhecer os erros é o mínimo se quisermos construir uma nação democrática. Temos que vencer a resistência, transformar em palavras tudo que está recalcado em nossa história. E de uma vez por todas, não tentar construir uma nova casa sobre as ruínas de uma antiga.

\section{Referências}

ADORNO, Theodor W, HORKHEIMER, Max. A dialética do esclarecimento. Rio de Janeiro: Jorge Zahar Editor, 1995.

DEAK, André. No Brasil, a tradição é o golpe. Revista Fórum, Santos, 01 abr. 2016.

Disponível em: https://www.revistaforum.com.br/no-brasil-a-tradicao-e-o-golpe/ Acesso em: 25 mar. 2018.

FREUD, S. (1911-1913). Obras completas de S. Freud. Rio de Janeiro: Companhia das Letras (1914). "Recordar, repetir e elaborar ", p.146-158.

HUYSSEN, Andreas. Seduzidos pela Memória. Arquitetura, monumento, mídia. 1. ed. Rio de Janeiro: Aeroplano Editora. 2000.

SELIGMANN-SILVA. Testemunho e a política da memória: o tempo depois das catástrofe. In: Proj. História, São Paulo, (30), p. 71-98, 2005. 
2010

O local do testemunho. In: Tempo e Argumento, Florianópolis, vol 2, n 1, p 3-20, 